\title{
Life Satisfaction in Correspondence with Self-Efficacy among Banking Sector Employees: A Study of Sitamarhi District, North Bihar
}

\author{
Ms. Rani Kumari
}

Research Scholar, University Department of Psychology, L. N. Mithila University, Darbhanga - 846 008, India

DOI:10.36348/sjhss.2020.v05i11.003 $\quad$ | Received: 30.10.2020| Accepted: 14.11.2020| Published: 19.11 .2020

*Corresponding author: Ms. Rani Kumari

\section{Abstract}

The present investigation was intended to ascertain the relationship between self-efficacy and life satisfaction among banking sector employees with particular reference to Sitamarhi district of North Bihar, India. The sample of the study consisted of 120 participants. The General Self-efficacy (GSE) scale was developed by Jerusalem and Schwarzer [1] and the Satisfaction with Life Scale (SWLS), created by Ed Diener [2], was used for the data collection. Having collected the data from the Bank employees of Sitamarhi district of North, Bihar, India, individual's score were obtained for giving statistical treatment. Pearson's correlation was applied to study the relationship between self-efficacy and life satisfaction while simple linear regression was used to examine the role of self-efficacy on life satisfaction. Results indicated that self-efficacy has its major impact on life satisfaction, whereas; Life satisfaction can reflect experiences that has influenced a person in a positive way. These experiences have the ability to motivate people to pursue and reach their respective goals. It is observed during the present study that people generally avoid tasks where they perceive the selfefficacy is low, but undertake tasks where self-efficacy is high. When self-efficacy is significantly beyond actual ability, it leads towards an overestimation of the ability to complete tasks. Obtained results have been discussed in detail by giving appropriate reasons.

Keywords: Self-efficacy, Life satisfaction and banking sector employees, Sitamarhi, North Bihar.

Copyright () 2020 The Author(s): This is an open-access article distributed under the terms of the Creative Commons Attribution 4.0 International License (CC BY-NC 4.0) which permits unrestricted use, distribution, and reproduction in any medium for non-commercial use provided the original author and source are credited.

\section{INTRODUCTION}

Self-efficacy is a learned human pattern of behavior rather than a genetically endowed one. It begins in infancy and continues throughout the life span. Self-efficacy is based on the premises of the Social Cognitive Theory which holds that humans actively shape their lives rather than passively reacting to environmental forces. Bandura [3] proposed that the developmental antecedents of Self-efficacy include:

i. Previous success in similar situations whereas, modeling in the same situations, watching other who has succeeded on a given arena and copying their actions.

ii. Imagining anyone behaving effectively, visualizing acting effectively to secure a wanted goal.

iii. Undergoing verbal persuasion by powerful, trustworthy, expert and attractive people.

iv. Arousal and Emotion. When we are physiologically aroused and experiencing negative emotions, our self-efficacy may be undermined. Whereas when such arousal is paired with positive emotions it heightens the sense of Self-efficacy.

"People who regard themselves
as highly efficacious act, think,
and feel differently from those
who perceive themselves as
inefficacious. They produce their
own future, rather than simply
foretell it" - Albert Bandura

Self-efficacy refers to an individual's belief in his or her capacity to execute behaviors necessary to produce specific performance attainments [4]. Selfefficacy reflects confidence in the ability to exert control over one's own motivation, behavior, and social environment. These cognitive self-evaluations influence all manner of human experience, including the goals for which people strive, the amount of energy expended toward goal achievement, and likelihood of attaining particular levels of behavioral performance. Unlike traditional psychological constructs, self-efficacy beliefs are hypothesized to vary depending on the domain of functioning and circumstances surrounding 
the occurrence of behavior. Self-efficacy, or our belief in our own abilities to deal with various situations, can play a pivotal role not only in how we feel about our self, but whether or not we successfully achieve our goals in life. According to Bandura [3] "Self-efficacy is people's beliefs in their own capabilities to realize desired effects by their own actions." Moreover, Todaka [5], has described Self-efficacy as "what I believe I can do with my skills under certain conditions."

According to Schunk [6], personal efficacy refers to a belief or expectation that one can successfully bring about changes. People with expectations are more likely to take risks, set more difficult goals, persist longer at chosen activities and be more involved in what they are doing.

Based on what needs to be done in order to reach a desired goal (these are called outcome expectancies), the person then analyses his or her capability to complete the necessary actions (these are called efficacy expectancies). According to Bandura [3], self-efficacy expectancies refer to convictions which one can successfully perform the behavior required to produce a given outcome, whereas, outcome expectancies are the beliefs that a given behavior will lead to that outcome. Bandura viewed that outcome expectancies are far less important than efficacy expectancies.

Judgments of self-efficacy are generally measured along with three basic scales: magnitude, strength, and generality as the descriptions are as follows:

Self-Efficacy Magnitude: Measures the difficulty level (e.g. easy, moderate, and hard) an individual feels is required to perform a certain task. How difficult is my class work? Are the quizzes easy or hard?

Self-efficacy strength: Refers to the amount of conviction an individual has about performing successfully at diverse levels of difficulty. How confident am I that I can excel at my work tasks? How sure am I that I can climb the ladder of success?

Generality of self-efficacy: Refers to the "degree to which the expectation is generalized across situations. How sure am I that what I have learned will apply to my new tasks?

The basic idea behind the Self-efficacy theory is that performance and motivation are in part determined by how effective people believe they can be.

According to Dinther, Dochy, \& Segers [7]some important factors affecting Self-efficacy that follows:

a. Mastery experience - individuals engage in tasks and activities, Interpret the results of their actions. They use the interpretations to develop beliefs about their capability to engage in subsequent tasks or activities and act in concert with the beliefs created. Typically, outcomes interpret as successful raise selfefficacy while those interpreted as failures lower it.

b. Modeling-People from their self-efficacy beliefs through the various experiences of observing others performs tasks. This is a process of comparison between a person and someone else. When people see others performing a task successfully, they imitate that behaviour when they are in a similar situation. Modeling is a powerful influence when an individual is particularly unsure of himself.

c. Social persuasion- Sometimes a person can be influenced by the advice or suggestions made by a powerful, trustworthy or acclaimed expert to behave in a certain manner.

d. Physiological factors- In unusual stressful situations, people commonly exhibit signs of distress, aches and pains, fatigue, fear or nausea. A person's perception of these responses can markedly alter his Self-efficacy. If a person feels really nervous before a public speech, a person with low self-efficacy may take this as a sign of their own inability, thus decreasing their Self efficacy even further. On the other hand a person with high self-efficacy is likely to interpret such physiological signs as normal and unrelated to his or her actual ability. Their self-efficacy will not be affected.

\section{Life Satisfaction}

According to Iwasaki [8], "Life satisfaction gives meaning to one's life and it can be source of a feeling or self-worth. In the Indian context, most of the elderly review their part life in terms of selffulfillment." Prasoon, \& Chaturvedi [9], defined life satisfaction is, "an assessment of the overall conditions of existence as derived from a comparison of one's aspiration to one's actual achievements." Whereas, Heller, Watson, \&Ilies [10], indicates that, "Life satisfaction is considered as a dynamic process which goes on throughout one's life."

According to Lemon, Bengtson, \& Peterson [11] in the Dictionary of Developmental Psychology, "life satisfaction is the degree of contentment with one's own life style." Life satisfaction is referred as an assessment of the overall conditions of existence as derived from a comparison of one's aspiration to one's actual achievement [12].

In the beginning of 1960's when life satisfaction became a big area of discussion in research then thereafter the term life satisfaction was originally thought to be measured objectively and externally. 
Since then, it has become evident that life satisfaction must be measured subjectively rather than objectively; techniques commonly used include, surveys, questionnaires, and interviews.

Measuring life satisfaction isn't just a way to see how happy people are with their lives; it's also a way of determining how unhappy they are. By adding another, positive point of view stemming from the individuals subjective experience, clinicians and researchers can analyze what makes people happy and what makes them unhappy.

Life satisfaction defined in a very simple and clear way, is not seen as this much easily understandable concept in reality. For this reason, many different definitions can be encountered.

\section{Importance of Life Satisfaction}

Need of Life satisfaction involves generally the whole life of a person and all the aspects of life. Life satisfaction is the dominance of positive feelings to the negative ones in the daily life and means to be good in different views such as happiness and moral [13].

The study on Life satisfaction is the need of the hour. It is of much importance in today's stressful life. Without satisfaction man cannot lead a peaceful and prosperous life. So, one must learn to break tensions, worries and anxieties of daily life. Otherwise these all will break him. Life satisfaction refers to an individual's well-being; quit is a state of feeling pleasure in an organism, which is ultimate goal that human beings are thriving to achieve in entire lives. Without life satisfaction, there is disharmony in the inner \& outer self. It gives rise to feeling of emptiness, uneasiness and meaninglessness in life. This paradoxical situation leads to crisis of character, values and working efficiency. Life satisfaction includes the capacity for enjoyment. The more we can enjoy what we have, the happier we are. A person having high life satisfaction is expected to have happy/higher adjustment with life and vice-versa.

Life satisfaction is attainment of a desired end and fulfillment of essential conditions [14]. Satisfaction in life does not lie in the length of days, but in the use we make of them. A man may live long yet may get little from life. Thus satisfaction in life does not depend on number of years, but on will [15]. It is a degree of contentment with one's own life style.

Ellis and Newton [16] psychologically speaking satisfaction may occur on a conscious, preconscious and unconscious level and brings an organism to a balanced state. Satisfaction with one's life implies a contentment with 'or' acceptance of one's life circumstances, or the fulfillment of one's wants and needs for one's life as a whole.
Dunn, Gilbert, \& Wilson [17] are of the view that a man would be completely happy if he is satisfied in all aspects of life. A life that involves the satisfaction of simple desires, gives many pleasures. These desires arise due to a number of behavioral actions that are related to overt or covert behavior of the concerned individual or these may be environmental i.e. related to social, mental and physical environment.

Shephard [18] analyzed nine life satisfaction variables such as satisfaction with relations, hobbies, place of residence, satisfying life (happy or dull), health conditions, physical fitness and health and overall satisfaction with one's life situations. Douthitt et al., [19] reported that economic variable significantly influenced economic and non-economic domains of life. Maynard [20] reported as the number of occupational roles increased, life satisfaction tended to decrease.

Cribb [21] found in his study the people become more satisfied with their lives, as they get older. This could be that as we age, we come to realize that most of the important things in life are not for sale. Among these are work satisfaction, friendship, pleasures of solitary thought, reading and other forms of non-commercial leisure.

Ansari and Khan [22] found that self-efficacy has its major impact on life satisfaction where Life satisfaction can reflect experiences that have influenced a person in a positive way. These experiences have the ability to motivate people to pursue and reach their respective goals. It is found that, People generally avoid tasks where they perceive the self-efficacy is low, but undertake tasks where self-efficacy is high. When selfefficacy is significantly beyond actual ability, it leads towards an overestimation of the ability to complete tasks. It means that for the satisfaction with life selfefficacy must be enhance either as a student, academician or professional.

\section{RATIONALE OF THE STUDY}

As per sample of the study is concerned, banking sector employees were selected. This group is on extreme of demand and need to have zeal and they are required to accomplish the assignment within given time period. They spend more time to achieve their satisfaction by several resources available at work place and around them. However, it can have wide-ranging adverse consequences that affect many domains of the individual's life e.g. interpersonal, social, occupational, psychological and physical. Perhaps the greatest negative impact tends to be on family and social life, because as excessive time spent at workplace often results in withdrawal of social activities, family, friends and interests. This way of working environment can lead to poor health. It is also an important factor for the worsening of cultural and moral values. Banking sector employees are investing their most of the time in 
working environment. That is why researcher was curious to study the life satisfaction among banking sector employees.

\section{OBJECTIVES OF THE STUDY}

Having reviewed the literature available on the phenomena, it has been observed that none of the studies are available with special reference to banking sector employees those who are living in Sitamarhi district of North Bihar, India and still the sample area undertaken for the present piece of research work is unexplored. Thus, the present study is of utmost value in the area concerned. Therefore, the present enquiry was aimed:

- To study the relationship between life satisfaction and self-efficacy among banking sector employees.

- To study the impact of self-efficacy on life satisfaction of banking sector employees.

\section{HYPOTHESES}

On the basis of the broad objectives of the study the following hypotheses were formulated.

i. There will be no relationship between life satisfaction and self-efficacy among banking sector employees.

ii. There will be no impact of self-efficacy on life satisfaction of banking sector employees.

\section{RESEARCH METHODOLOGY}

\section{Sample}

Participants of the study consisted of 120 banking sector employees; they were selected from different private and nationalized bank located in and around Sitamarhi district. Total subjects' age were ranged between 25 to 45 years.

\section{TOOLS USED}

1. General Self-Efficacy Scale-Hindi Version (GSE-H): General Self-Efficacy (GSE) scale a developed by Jerusalem and Schwarzer (1992) was used. He first developed originally the German version of this scale as 20 -items and later he translated this scale into German to English and reduced 10-items [1]. After a short period of time Sud [23] also translated this scale from English to Hindi version. Therefore, general self-efficacy scale (Hindi version) consists of 10 -items rated on four point rating scale with the response categories i.e. (1) not at all true, (2) hardly true, (3) moderately true, and (4) exactly true. For scoring, all the ten items are added to yield the final composite score with a range from 10-40. The reliability coefficient of the scale was found to be ranging 0.76 to 0.90 .

2. Satisfaction with life scale:The Satisfaction with Life Scale (SWLS), created by Ed Diener [2], has been one of the more applicable measurement tests of life satisfaction. It consists of five statements (e.g. the conditions of my life are excellent) to which the participant indicates their agreement. This assessment doesn't specify explicit domains such as financial or health satisfaction; it allows subjective evaluation of life as a whole. According to the research conducted on the validity of life satisfaction scales, one of the main measurements is based on preferences and values of people [24]. Though they share the same world and same value since they experience things and view life differently.

3. Biographical Information Blank: Biographical information blank was also prepared for interpreting the results. It includes: age, sex, qualifications, number of dependents, family type, salary and total family income, etc.

\section{Statistical Analyses}

In order to meet the research objectives data was analyzed through Pearson's Product Moment Correlation to study the relationship between life satisfaction and self-efficacy. Further, Simple Linear Regression was applied to assess the impact of selfefficacy on life satisfaction among banking sector employees.

\section{Procedures}

All the above measures in printed forms were administered on each banking employees by saying that the responses on the items of the schedules given by you will be kept strictly confidential and will be used research purposes only. After collecting the data through questionnaire schedules, the individual scores were tabulated as per norms and procedure of the measures used for giving statistical treatment. Finally, obtained results were presented in the tables.

\section{RESULTS AND DISCUSSION}

Table-1: Shows correlation between Self-efficacy and Life Satisfaction among banking sector employees

\begin{tabular}{|l|l|l|}
\hline \multicolumn{3}{|c|}{ Correlations } \\
\hline \multirow{3}{*}{ Self-Efficacy } & Pearson Correlation & $.565^{* *}$ \\
\cline { 2 - 3 } & Sig. (2-tailed) & .000 \\
\cline { 2 - 3 } & $\mathrm{N}$ & 120 \\
\hline **. Correlation is significant at the 0.01 level (2-tailed). \\
\hline
\end{tabular}


Table-1 indicates that self-efficacy in significantly and positively correlated with life satisfaction $(\mathrm{r}=.565, \mathrm{p}<.001)$ among banking sector employees. It means that as self-efficacy increases life satisfaction also increases and vice versa.

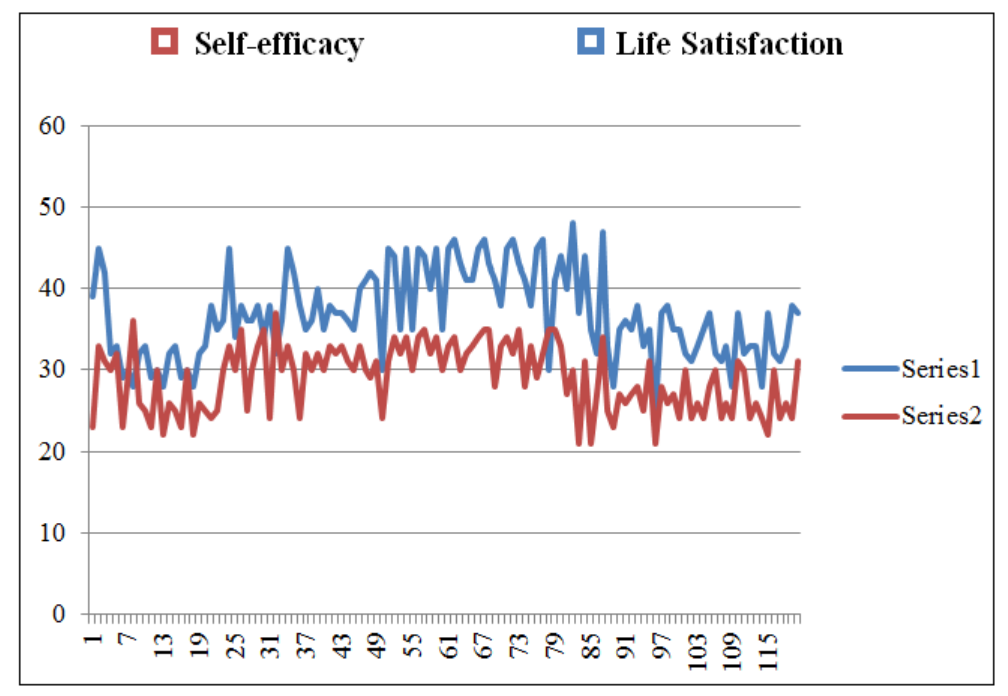

Line graph represents the correlation between self-efficacy and life satisfaction, scores of banking sector employees; it also exhibits the score range that is 21 to 48 .

Table-2: Show simple Linear Regression analysis, Self-efficacy as a predictor of life satisfaction among overall students

\begin{tabular}{|l|l|l|l|l|}
\hline \multicolumn{4}{|c|}{ Model Summary } \\
\hline Model & R & R Square & Adjusted R Square & Std. Error of the Estimate \\
\hline 1 & $.565^{\text {a }}$ & .319 & 313 & 3.388 \\
\hline \multicolumn{3}{|c|}{ a. Predictors: (Constant), Self-Efficacy } & \\
\hline
\end{tabular}

Summary Table- 2 provides the value of $R$ and $R^{2}$ for that has been derived. Whereas, $R$ has a value of .565 and because there is only one predictor, this value represents the simple correlation between self-efficacy and life satisfaction among overall students. The value of $R^{2}$ is .319 , which tells us that self-efficacy can account for $31.9 \%$ of the variation in life satisfaction. This means that $68.1 \%$ of the variation in life satisfaction cannot be explained by self-efficacy alone. Therefore, there must be other variables that have an influence also on life satisfaction of overall students.

Table-3: Showing F-value (ANOVA table)

\begin{tabular}{|c|c|c|c|c|c|c|}
\hline \multicolumn{7}{|c|}{ ANOVA $^{b}$} \\
\hline \multicolumn{2}{|c|}{ Model } & Sum of Squares & df & Mean Square & $\mathbf{F}$ & Sig. \\
\hline \multirow[t]{3}{*}{1} & Regression & 634.479 & 1 & 634.479 & 55.282 & $.000^{\mathrm{a}}$ \\
\hline & Residual & 1354.312 & 118 & 11.477 & & \\
\hline & Total & 1988.792 & 119 & & & \\
\hline \multicolumn{4}{|c|}{ a. Predictors: (Constant), Self-Efficacy } & & & \\
\hline \multicolumn{4}{|c|}{ b. Dependent Variable: Life Satisfaction } & & & \\
\hline
\end{tabular}

The ANOVA Table- 3 shows the various sums of squares and the degrees of freedom associated with each. From these two values, the average sum of squares (the mean squares) has been calculated by dividing the sums of squares by the associated degrees of freedom. The most important part of the table is $F$ - ratio, which is calculated using equation, and associated significance value of that $F$-ratio. In this table, $F$ is 55.28, which is significant at $p<.001$ (because the value in the column labelledSig. is less than .001)this result tells us that there is less than $0.1 \%$ chance that selfefficacy has no influence on life satisfaction of students. 
Table-4: Show the Coefficients details of Self-efficacy and Life satisfaction among overall students

\begin{tabular}{|l|l|l|l|l|l|l|}
\hline \multicolumn{2}{|c|}{ Model } & Un-standardized Coefficients & Standardized Coefficients & \multirow{2}{*}{ t } & \multirow{2}{*}{ Sig. } \\
\cline { 3 - 7 } \multicolumn{2}{|l|}{1} & B & Std. Error & Beta & & \\
\hline \multirow{2}{*}{1} & (Constant) & 13.288 & 2.141 & & 6.206 & .000 \\
\cline { 2 - 6 } & Self-Efficacy & .428 & .058 & .565 & 7.435 & .000 \\
\hline \multicolumn{2}{|l|}{ a. Dependent Variable: Life Satisfaction } & & & \\
\hline
\end{tabular}

Whereas, Table-4 shows that $b_{1}$ value (i.e. $.428)$ which represents $42.8 \%$ chances are there that when self-efficacy will increase life satisfaction will also increase and vice versa. The Value of Beta is = .565 for which t-value is also significant at the level of .001 level of significance which indicates that Self efficacy has positive and significant influence on life satisfaction among overall students.

\section{CONCLUSIONS}

Consequently, we can irrespectively say that life satisfaction and self-efficacy positively and significantly correlated with each other especially in Sitamarhi district where from the present study has been carried out on the banking sector employees. It means that those employees who are having high level of selfefficacy, most probably they will have good level of life satisfaction. As we know that those employees having characteristics of good skills are able to adjust with the environment as well as critical circumstances and relationships e.g. society, colleagues, family and friends. They will feel comfortable in team work and their productivity also will be also high. Several researches conducted in the different geographical areas on the mentioned variables come to a central idea that high self-efficacy is an skill to better deal with the social as well as personal problems. To be happy and live a satisfied life it's necessary to feel free from stress and different life challenges. It's clear that people having high level of self-efficacy most probably will deal with life challenges effectively and in correspond with they will have better life and balance.

So, we can say that those employees of banking sector will have high level of self-efficacy they will also have better level of life satisfaction; because they would be able to deal with their demanding job very effectively and feel ease towards their assignments which will lead them towards life satisfaction.

\section{REFERENCES}

1. Jerusalem, M., \& Schwarzer, R. (1992). Selfefficacy as a resource factor in stress appraisal processes. Self-efficacy: Thought control of action, 195213.

2. Diener, E. D., Emmons, R. A., Larsen, R. J., \& Griffin, S. (1985). The satisfaction with life scale. Journal of personality assessment, 49(1), 71-75.
3. Bandura, A. (1982). Self - efficacy mechanism in human agency. American psychologist. 37(2): 122147.

4. Porter, L. W., Bigley, G. A., \& Steers, R. M. (2003). Motivation and work behavior.

5. Todaka, Y. (2013). Self-efficacy theory and beyond: Japanese college EFL learners. Journal of Educational and Social research, 3(7), 359.

6. Schunk, D. H. (1995). Self-efficacy, motivation, and performance. Journal of applied sport psychology, 7(2), 112-137.

7. Dinther, V. M., Dochy, F., \&Segers, M. (2011). Factors affecting students' self-efficacy in higher education. Educational research review, 6(2), 95108.

8. Iwasaki, Y. (2007). Leisure and quality of life in an international and multicultural context: What are major pathways linking leisure to quality of life?. Social Indicators Research, 82(2), 233-264.

9. Prasoon, R., \&Chaturvedi, K. R. (2016). Life satisfaction: a literature review. The ResearcherInternational Journal of Management Humanities and Social Sciences, 1(2), 25-32.

10. Heller, D., Watson, D., \&Ilies, R. (2006). The dynamic process of life satisfaction. Journal of personality, 74(5), 1421-1450.

11. Lemon, B. W., Bengtson, V. L., \& Peterson, J. A. (1972). An exploration of the activity theory of aging: Activity types and life satisfaction among in-movers to a retirement community. Journal of gerontology, 27(4), 511-523.

12. Saad, J. (2020). Self-Esteem and Life Satisfaction amongst Afghan and Indian University Students. International Journal of Creative Research Thoughts (IJCRT), ISSN, 2320-2882.

13. Cummins, R. A., \&Nistico, H. (2002). Maintaining life satisfaction: The role of positive cognitive bias. Journal of Happiness studies, 3(1), 37-69.

14. Sirgy, M. J. (2012). The psychology of quality of life: Hedonic well-being, life satisfaction, and eudaimonia (Vol. 50). Springer Science \& Business Media.

15. Schwarz, N., \&Strack, F. (1999). Reports of subjective well-being: Judgmental processes and their methodological implications. Well-being: The foundations of hedonic psychology, 7, 61-84.

16. Ellis, R. D., \& Newton, N. (2000). The interdependence of consciousness and emotion. Consciousness \& Emotion, 1(1), 1-10.

17. Dunn, E. W., Gilbert, D. T., \& Wilson, T. D. (2011). If money doesn't make you happy, then 
you probably aren't spending it right. Journal of Consumer Psychology, 21(2), 115-125.

18. Shephard, G. H. (1997). Church related continuum of care retirement centers in Oklahoma: life satisfaction of residents (Doctoral dissertation, Oklahoma State University).

19. Douthitt, R. A., MacDonald, M., \& Mullis, R. (1992). The relationship between measures of subjective and economic well-being: A new look. Social Indicators Research, 26(4), 407-422.

20. Maynard, M. (1993). A comparison of female professionals' role profiles with occupational adjustment and life satisfaction. Journal of employment counseling, 30(3), 133-142.
21. Cribb, K. (2000). Life satisfaction, and who has it. National Undergraduate Research Clearinghouse [on-line]. Доступно в Интернет: http://www. webclearinghouse. net.

22. Ansari, M., \& Khan, S. A. (2015). Self-efficacy as a predictor of life satisfaction among undergraduate students. The International Journal of Indian Psychology, 2(2), 5-11.

23. Baxter III, W. V., Sud, A., Govindaraju, N. K., \&Manocha, D. (2002). GigaWalk: Interactive Walkthrough of Complex Environments. Rendering Techniques, 2002, 203.

24. Diener, E., Inglehart, R., \&Tay, L. (2013). Theory and validity of life satisfaction scales. Social Indicators Research, 112(3), 497-527. 